\title{
Acute effects of exposure to orthochloro- benzylidene malononitrile (CS) and the development of tolerance
}

\author{
F. W. BESWICK, P. HOLLAND, and K. H. KEMP \\ Chemical Defence Establishment, Porton Down, Wilts
}

\begin{abstract}
Beswick, F. W., Holland, P., and Kemp, K. H. (1972). Brit. J. industr. Med., 29, 298-306. Acute effects of exposure to orthochlorobenzylidene malononitrile (CS) and the development of tolerance. Of the many compounds capable of producing irritation of the eyes and upper respiratory tract two, $\omega$-chloroacetophenone and orthochlorobenzylidene malononitrile (CS), have been used as riot control agents. The latter, CS, has been in use for more than 10 years and is currently still in service. When dispersed as a smoke consisting of 1-micron diameter particles CS will produce lachrymation and pain and discomfort in the upper respiratory tract and chest. Exposed individuals become apprehensive and highly motivated to escape from the smoke. Recovery from these effects occurs within minutes of the affected individual reaching fresh air.

The present study reports the effects produced by CS aerosol on 35 healthy male volunteers who were exposed in such a way that the total dose of the agent received by each man was greater than that which he might have received in an actual riot; this was achieved by taking advantage of the fact that adaptation to the effects of CS occurs if exposure is gradual and to low concentrations. In addition to the clinical observations, cardiological, respiratory, and biochemical observations were made. No abnormalities were observed in the electrocardiogram, respiratory function tests or the blood biochemistry and cell constitution. Such changes that were observed could be ascribed to the emotional stress and discomfort of the experiment.
\end{abstract}

Many compounds, when disseminated as vapour or aerosol, are capable of producing, in man, irritation of the eyes and upper respiratory tract; two in particular, $\omega$-chloroacetophenone $(\mathrm{CN})$ and $\mathrm{O}$ chlorobenzylidene malononitrile (CS), are highly potent and specific in producing these effects and for this reason have been utilized as the active ingredient of tear smoke.

CN (also known as C.A.P.) has been in service much longer than CS; its major effects, produced at a concentration of about $20 \mathrm{mg} / \mathrm{m}^{3}$, are the almost immediate onset of irritating pain in the eyes accompanied by blepharospasm, severe lachrymation, and irritation of the nose. At higher concentrations, or after prolonged exposure, there may be a mild conjunctivitis with photophobia and stinging or pain in exposed skin. Serious consequences, including death, might occur in healthy individuals when exposures at least some 700 times greater than those likely to occur in practice are experienced (Stein and Kirwan, 1964).

CS, which has been in service for more than 10 years, is the only riot control agent likely to be encountered in Great Britain, and its properties have been described in Patent 967660 (Finn, Hogg, and Crichton, 1960) and its toxicology by Ballantyne and Callaway (1972a and b). Dispersed from munitions in particles of about $1 \mu$ mass median diameter, it is effective between one-tenth and one-fifth of the equipotent concentration of $\mathrm{CN}$. CS acts on exposed 
sensory nerve endings and therefore the signs and symptoms which follow exposure to aerosols are principally in the eyes and respiratory tract. Typically, there is an almost instant and severe inflammation of the conjunctivae accompanied by pain in the eyes, excessive lachrymation, and blepharospasm; there is irritation and running of the nose, a burning sensation in the throat, and a feeling of intense discomfort during which the subject coughs, often violently. If the exposure is continued, the discomfort spreads to the chest, there is difficulty in breathing, and many subjects describe tightness or even pain. The respiratory pattern is irregular and the breath is held for short periods. At this stage most individuals are acutely apprehensive and are highly motived to escape from the smoke. Within minutes of being removed from the CS there is relief from all major effects and after 10 minutes only moderate lachrymation with some redness of the eyelids remains. If the exposed individual is sufficiently determined to remain in the CS aerosol, even when the peak of discomfort has been reached, there is evidence that some remission of signs and symptoms occurs although they never become insignificant. To investigate any development of tolerance to $C S$, Punte, Owens, and Gutentag (1963) exposed four subjects to each of four conditions: (a) a concentration of $1.5 \mathrm{mg} / \mathrm{m}^{3}$ for 90 minutes; $(b)$ a concentration of $1.5 \mathrm{mg} / \mathrm{m}^{3}$ rising rapidly after 40 minutes to $11.0 \mathrm{mg} / \mathrm{m}^{3} ;(c)$ a concentration of $6 \mathrm{mg} / \mathrm{m}^{3}$ attained in 10 minutes; and $(d)$ a concentration of $6.6 \mathrm{mg} / \mathrm{m}^{3}$ attained slowly over 30 minutes. The subjects were unaware that the concentrations would be increased. These concentrations all produced the typical effects of CS in all the subjects. In exposure $(a)$, all the men remained in the chamber for 90 minutes, and in exposure $(b)$ they all remained until the boost after 40 minutes. In exposure (c), only one subject could endure the CS for more than 30 minutes, while in exposure $(d)$ all four subjects were still in the chamber at 60 minutes. The inference is that tolerance develops to relatively high concentrations of CS, provided that they are attained slowly. On the other hand, when seven men were exposed 10 times in two weeks to concentrations of between 1.0 and $13.0 \mathrm{mg} / \mathrm{m}^{3}$, no subject developed any noticeable tolerance.

As acute human exposures are self-limiting, in that the material can be tolerated for only a very short time, it is necessary to exploit the occurrence of tolerance in order to investigate the effects of inspired doses larger than those encountered in practical situations. The nature of the tolerance itself, however, is also important and in this study both these factors have been examined.

\section{Methods}

The subjects were 35 healthy male volunteers who had no history of respiratory disorder, skin disease or allergy. Every individual was subjected to a full medical examination, including a chest radiograph, immediately before and after exposure to CS aerosol. Most individuals were re-examined 24 hours later and some were seen up to three weeks after exposure with no evidence of after effects.

In addition the following special investigations were made:

\section{Haematology}

Blood samples were taken from the median cubital vein of 16 volunteers before, after, and 24 hours following exposure; measurements were made of haemoglobin concentration, packed cell volume (PCV), mean cell haemoglobin concentration (MCHC), erythrocyte sedimentation rate (ESR), white blood cell count, and differential leucocyte count.

\section{Blood biochemistry}

From the same blood samples aliquots were taken for the assay of serum aspartate aminotransferase (SGOT), serum alanine aminotransferase (SGPT), alkaline phosphatase, bilirubin, total protein, albumin and globulin, electrolytes, bicarbonate, and urea.

\section{Cardiology}

Electrocardiograms were made before and after exposure, and the blood pressure was measured before and during exposure on a limited number of volunteers.

\section{Respiratory function}

Measurements were made of peak flow, tidal volume, and vital capacity before and after exposure on 26 volunteers.

Exposures to CS, which lasted for 60 minutes, were carried out in a $100-\mathrm{m}^{3}$ chamber in which the CS cloud was put up by ignition of 1-g pellets of CS (Pellet, Irritant, Smoke, Respirator Testing L1A1) in trials 1 to 6, and by specially prepared pyrotechnic devices similar to cartridges, in trials 7 to 10 .

There were 10 separate trials and details of the number of volunteers in each and the concentrations of CS attained are given in Table 1. In the first three, the concentration was kept relatively low and constant throughout; in the remaining trials the CS concentration was made to rise progressively over 60 minutes to reach a final value in the neighbourhood of $2 \mathrm{mg} / \mathrm{m}^{3}$.

In all except trials 1 and 2 the chamber was first saturated with CS one hour before the start and then blown through to expel all the CS not absorbed on the walls or on the equipment. The volunteers, varying in number from two to eight (see Table 1), then entered the chamber wearing respirators and protective overalls. The $\mathrm{CS}$ was generated and allowed to mix for 3 minutes before the respirators were removed. During the 60minute exposure, the CS concentration was boosted at the intervals shown in Table 1. Samples of the CS atmosphere were taken for analysis at approximately 10-minute intervals.

Trials 5 and 6 differed from the others in that the same eight men took part in both, to a cross-over design. However, four removed their respirators at the start of the 60-minute exposure and four removed theirs only at the end. In this way it was possible to judge the extent to 
TABLE 1

Concentrations of CS DURING 60-Minute Exposure

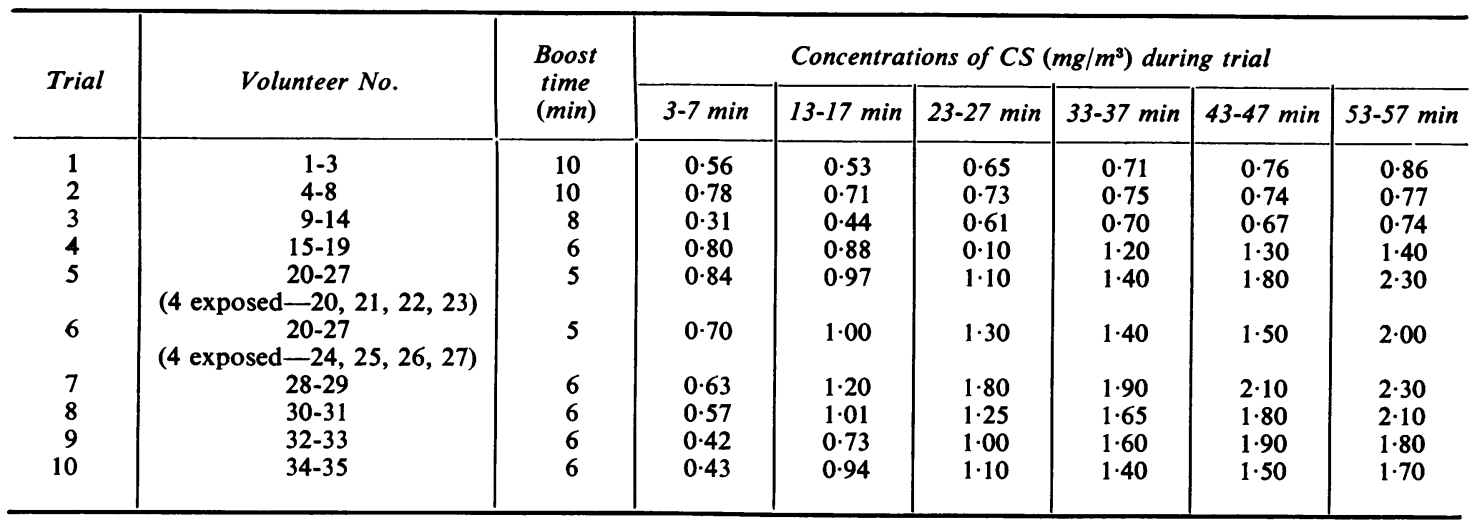

which the first four had become tolerant. During their exposures, the men were encouraged not to voice their symptoms so that they would not suggest effects to their fellows. After exposure, and on completion of the medical examination and tests, the men were interviewed individually, to record the symptoms which they had experienced and their subjective assessment of their severity. This information was supplemented by observations made while the men were in the chamber and is the basis of Table 3, which summarizes the incidence of the various effects observed and complained of. For convenience of discussion, some consolidation of results has been necessary, following the scheme shown in Table 2. The men themselves were too occupied with the symptoms to furnish any firm estimates of the times of onset or termination, and it was difficult for observers to time, reliably, the duration of signs which rarely presented a clearly defined start and finish.

\section{Results}

Of the 35 men participating in the experiment, one man quitted the chamber after 8 minutes (trial 3, group II), one left at 55 minutes to vomit, and the remainder stayed for the full 60 minutes. These results refer to the effects reported by the 34 men who stayed for 55 minutes or longer. Because of the small sample sizes, no statistical significance can be attached to possible variations of pattern for different conditions. The effects in the man leaving at 8 minutes were severe stinging of the eyes, irritation of the throat, cough and dyspnoea, and salivation; he also complained of nausea.

\section{Onset of effects}

On first removing their respirators, all of the subjects found the effects very unpleasant. After 4 or 5 minutes most of them found the symptoms more tolerable and were able to play cards, and two even attemped to read, despite the eye effects and the constant need to spit. At interview, these men did not necessarily consider that the symptoms had de-

TABLE 2

Grouping of Subjects Adopted for Assessment of Symptoms

\begin{tabular}{|c|c|c|c|c|c|}
\hline \multirow{2}{*}{$\begin{array}{l}\text { Group } \\
\text { No. }\end{array}$} & \multirow{2}{*}{$\begin{array}{l}\text { Nominal increase } \\
\text { in concentration }\end{array}$} & \multirow{2}{*}{$\begin{array}{l}\text { Trial } \\
\text { No. }\end{array}$} & \multirow{2}{*}{$\begin{array}{l}\text { Subject } \\
\text { No. }\end{array}$} & \multicolumn{2}{|c|}{ Concentration } \\
\hline & & & & $\begin{array}{c}\text { Initial } \\
\left(m g / m^{3}\right)\end{array}$ & $\underset{\left(m g / m^{3}\right)}{\text { Final }}$ \\
\hline $\begin{array}{l}\text { I } \\
\text { II } \\
\text { III } \\
\text { IV } \\
\text { V }\end{array}$ & $\begin{array}{c}\text { Steady } \\
\text { X2 } \\
\text { X2 } \\
\text { X3 } \\
\text { X4 }\end{array}$ & $\begin{array}{r}2 \\
1 \\
3 \\
4 \\
5 \\
6 \\
7 \\
8 \\
9 \\
10\end{array}$ & $\begin{array}{c}4-8 \\
1-3 \\
9-14^{1} \\
15-19 \\
20-23 \\
24-27 \\
28-29 \\
30-31 \\
32-33 \\
34-35\end{array}$ & $\begin{array}{l}0.78 \\
0.56 \\
0.31 \\
0.80 \\
0.84 \\
0.70 \\
0.63 \\
0.57 \\
0.42 \\
0.45\end{array}$ & $\begin{array}{l}0 \cdot 77 \\
0 \cdot 86 \\
0 \cdot 74 \\
1 \cdot 40 \\
2 \cdot 30 \\
2 \cdot 00 \\
2 \cdot 30 \\
2 \cdot 10 \\
1 \cdot 80 \\
1 \cdot 70\end{array}$ \\
\hline
\end{tabular}

${ }^{1}$ No. 10 withdrew within 8 minutes and is excluded from the table of symptomatology. 
creased in intensity but that they had become used to them. The surprise effects of the first symptoms may therefore be important in deciding the effectiveness of agents such as CS. Men who attempted to defeat the agent by holding their breath reported particularly unpleasant experiences when they took their first deep breath.

All the subjects could specify the first effects that they personally experienced, and most could identify the second effects; thereafter discrimination was difficult. Twenty-one men found that their eyes were affected first, irritation and watering developing practically simultaneously; another seven experienced irritation of the nose, four experienced irritation of the throat, one coughed, and one "had difficulty in breathing'. Thirty-one men considered that they could identify the second effects. Ten specified the eyes, seven the nose, and six a cough; three reported some difficulty in breathing, two irritation of the throat, and one tingling of the face. Two subjects reported an unusual taste in the mouth.

Incidence of effects during exposure (Table 3) Eyes Thirty-two subjects reported a stinging sensation of the eyes, and most experienced blepharospasm, usually in the early part of the exposure. For 24 subjects the stinging lasted, relatively unchanged, throughout the exposure, and one man considered that it got worse. Five subjects suffered periodic discomfort when the CS concentration was boosted. Thirty-two men experienced lachrymation, and for 21 of them this effect persisted throughout the whole exposure. Seven reported this effect to increase temporarily following each boost, and one man, who endured a threefold increase in concentration, considered that lachrymation increased throughout the experiment. One subject complained of photophobia, which decreased with time.

Overall there did not appear to be any obvious connexion between the severity of these effects and the concentrations to which the men were exposed, although the duration of the symptoms may have been less when concentrations were kept relatively constant throughout the hour (group I).

Nose Eighteen subjects reported stinging of the nose, although only 12 experienced this continuously throughout the experiment. Thirteen reported a 'peppery' sensation, persisting in seven subjects and increasing in intensity in one. The persistence of the nasal irritation was marginally less when CS concentrations remained relatively constant.

Twenty-eight men experienced rhinnorrhoea, persistent in 23 of them; 11 complained of blocked noses, usually in association with the production of excessive mucus. These effects diminished in subjects exposed to constant CS concentrations or to concentrations which were merely doubled over the 60 minutes.

Mouth Irritation of the mouth (in one case the tongue only), described as a stinging or burning sensation, was reported by 15 men and lasted throughout the experiment in 10 instances. All subjects suffered from excessive production of mucus and saliva, which was regarded as a considerable

TABLE 3

Symptoms and Their Frequency Complained of by 34 Men Exposed to CS Aerosol

\begin{tabular}{|c|c|c|c|c|c|c|c|c|c|c|}
\hline & & & & & \multicolumn{6}{|c|}{ No. of volunteers affected in group } \\
\hline & & & & & $I$ & $I I$ & $I I I$ & $I V$ & $\boldsymbol{V}$ & Total No. \\
\hline 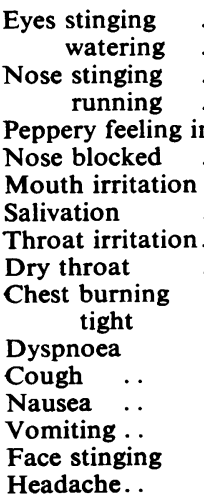 & $\begin{array}{l}\ldots \\
\ldots \\
\ldots \\
\text { n nose } \\
\ldots \\
\ldots \\
\ldots \\
\ldots \\
\ldots \\
\ldots \\
\ldots \\
\ldots \\
\ldots\end{array}$ & $\begin{array}{l}\cdots \\
\cdots \\
\cdots \\
\cdots \\
\cdots \\
\cdots \\
\cdots \\
\cdots \\
\cdots \\
\cdots \\
\cdots \\
\ldots\end{array}$ & $\begin{array}{l}\cdots \\
\cdots \\
\cdots \\
\cdots \\
\cdots \\
\cdots \\
\cdots \\
\cdots \\
\cdots \\
\cdots \\
\cdots \\
\ldots \\
\ldots\end{array}$ & $\begin{array}{l}\cdots \\
\cdots \\
\cdots \\
\cdots \\
\cdots \\
\cdots \\
\cdots \\
\cdots \\
\cdots \\
\cdots \\
\cdots \\
\cdots \\
\cdots\end{array}$ & $\begin{array}{l}5 \\
5 \\
3 \\
3 \\
2 \\
1 \\
2 \\
5 \\
4 \\
- \\
2 \\
1 \\
5 \\
2 \\
- \\
5 \\
2\end{array}$ & $\begin{array}{l}8 \\
8 \\
4 \\
7 \\
4 \\
3 \\
4 \\
8 \\
5 \\
1 \\
2 \\
3 \\
2 \\
2 \\
3 \\
-7 \\
7 \\
1\end{array}$ & $\begin{array}{l}4 \\
5 \\
1 \\
3 \\
2 \\
2 \\
-5 \\
5 \\
3 \\
- \\
- \\
2 \\
2 \\
4 \\
1 \\
1 \\
4 \\
5 \\
2\end{array}$ & $\begin{array}{l}7 \\
7 \\
6 \\
8 \\
4 \\
3 \\
6 \\
8 \\
6 \\
6 \\
3 \\
2 \\
2 \\
3 \\
3 \\
1 \\
7 \\
1\end{array}$ & $\begin{array}{l}8 \\
7 \\
4 \\
7 \\
5 \\
2 \\
3 \\
8 \\
5 \\
1 \\
1 \\
3 \\
3 \\
4 \\
2 \\
1 \\
8 \\
-\end{array}$ & $\begin{array}{r}32 \\
32 \\
18 \\
28 \\
17 \\
11 \\
15 \\
34 \\
23 \\
8 \\
8 \\
11 \\
9 \\
18 \\
11 \\
2 \\
32 \\
6^{1}\end{array}$ \\
\hline
\end{tabular}

13 Post-exposure. 
embarrassment. This was the only universal effect noted, and it continued throughout the exposure for all but seven men; no obvious connexion was observed between the initial CS concentration or the extent of its subsequent rise and the intensity or duration of salivation. The secretions were sometimes so copious that, at first sight, a man spitting them out looked as if he was vomiting. The only true instances of vomiting (see below) appeared to follow the swallowing of CS-laden saliva.

Throat 'Sore throat', 'burning throat', 'irritated throat', etc. were complained of, some men distinguishing between these as separate symptoms, others using the terms as synonyms. For simplicity all those reporting such effects have been grouped together; some sort of irritation was reported by 23 men, for 15 of whom it persisted throughout the exposure. Dryness of the throat was reported by eight men, lasting throughout their exposure.

Chest Eight men experienced some sort of burning sensation in the chest, persistent in three only. Eleven complained of tight chest, and nine had some difficulty in breathing; six of them experienced this only on first breathing the smoke, and one reported that the symptom declined in intensity with time. Eighteen men reported coughing, although this tended to be sporadic rather than continuous, and in nine instances coughing occurred only initially or else it decreased considerably with time.

The more severe effects, particularly difficulty in breathing, appeared to be consequent upon deep breaths which all the men who held their breaths were eventually forced to take.

Gastrointestinal Two subjects complained of 'wind', which decreased during exposure. Eleven reported 'nausea', which for seven of them was transient or decreased in severity. Only two men vomited, one within the first 5 minutes soon after removing his respirator, and the other at 55 minutes, when he left the chamber. Both instances were isolated and appeared to follow the swallowing of large quantities of saliva, despite a warning given before entering the chamber that, if possible, men were to avoid swallowing excess saliva.

Skin irritation All but two men experienced some stinging of the facial skin, which for 24 continued throughout the experiment. Generally, this effect appeared to have been of shorter duration in group I where CS concentration remained constant. Stinging appeared to be most unpleasant in the regions which were shaved, but two men complained of stinging around the mouth and chin in areas moistened by dripping mucus and saliva. Nine reported stinging of the skin around the ears, the back of the neck, and the backs of the hands. This was usually slight, rapidly decreased in intensity, and was probably more common at high initial concentrations.

Headache Three men developed headaches which lasted throughout the exposure. From the description of the symptoms these appear to have been due to irritation of the frontal sinuses.

\section{Persistence of symptoms after exposure}

Symptoms produced by CS disappear when the subject moves to clear air. Some CS may be desorbed from clothing, hair, etc. and may produce a temporary recurrence of minor effects, for example of the eyes, and stinging of the beard area, but these effects are minimized when, as in the present experiments, protective overalls are worn. Generally, symptoms disappear spontaneously within 10 minutes of moving into clear air, but occasionally effects not attributable to secondary contamination do persist, usually in a less severe form. In these experiments 10 individuals reported persistent symptoms, usually only one each, although one man (group III) reported four.

The most common complaint, made by six men, was of headache. Three of them did not develop the symptom until after leaving the chamber. Other effects reported comprised rhinorrhoea in two men, and single instances of blocked nose, cough, nausea, tightness of the chest, and eye symptoms. Generally, these did not last for more than $\mathbf{3 0}$ minutes, although in the three instances of headache the symptom persisted for somewhat longer. There was no recurrence of vomiting and no other gastrointestinal effects were reported.

\section{Subjective unpleasantness of the effects}

Each subject was asked what he considered to be the most unpleasant effect that he had experienced. Eye symptoms were specified by at least half of the men in each of the exposure groups, a total of 20 subjects. Four others disliked most the irritation of the throat, three the coughing, two the nose symptoms, two the tightness of the chest, and one each difficulty in breathing, nausea, and tingling of the face. Surprisingly, these symptoms were not always the ones rated as severe when a man gave an account of his general symptomatology, neither did they objectively always appear to be the most severe effects. Subjects questioned on this point stated that, while the specified effects were not necessarily the most severe, they had been the most unpleasant to tolerate.

\section{Development of tolerance during long exposures}

Provided that they did not bolt from the chamber at the first experience of the effects of CS, it was found that men could stay in CS in the circumstances of this study for over one hour, despite the fact that the concentration was increased up to fourfold during 
this time. Many effects were noticed only initially, and others tended to decrease in intensity with time, particularly for group I. Some symptoms occurred briefly immediately after boosting the CS concentration.

The subjects forming group IV (trials 5 and 6) were used to demonstrate, objectively, the growth of tolerance. During each exposure four subjects were unprotected for the full hour; another four, who were able to observe the unprotected men, wore respirators until 5 minutes from the end of the experiment, when they removed them. The eight subjects were em. ployed in both roles following a simple cross-over experimental design. Seven of the subjects were able to tolerate the CS, unprotected, for the full hour; the eighth left slightly before the end to vomit. When the same men removed their respirators after a fourfold increase in concentration only one man was able to stay for longer than one minute, and five left within 30 seconds of removing their respirators. Because of their brief exposures, it is doubtful whether these men, on this occasion, developed all the effects which might have been anticipated. In general, they complained of intense discomfort in the eyes and throat, several were severely nauseated, and one vomited (the same man who vomited when exposed unprotected). They tended to rate the burning in the throat as more unpleasant than the eye effects. Objectively, they appeared considerably more distressed than the men who had endured the CS for one hour.

\section{Haematology}

Table 4 contains means and standard deviations for the haematological findings from 16 of the volunteers, measured before, immediately after, and 24 hours following the CS exposure. The volunteers chosen were those who took part in trials $1,2,5$, and 6 (see Table 1). The values recorded do not indicate changes of pathological significance of any of the parameters as a result of exposure to CS. A very few individual control values were found to be just beyond the limits of generally accepted normality but these are very unlikely to have significance. However, if the various haematological parameters were examined, for each individual subject, from the point of view of variations during the entire duration of the experiment, there was an indication of a pattern of change. The pattern affects only some of the values measured but, with a few exceptions, it applies generally to all subjects. Thus there is a tendency for certain values to change shortly after CS exposure and for them to have returned to control levels 24 hours later. For this reason it was decided to examine the statistical significance of the mean differences between the control values, on the one hand, and the post-exposure and 24-hour values on the other, and these are also given in Table 4.

The total leucocyte count, compared to the controls, and the neutrophil count were both significantly raised $(P<0.01)$ when they were measured immediately following the CS exposure; even at 24 hours the total leucocyte count, although within normal limits, was still above the control. Less marked immediate rises $(P<0.05)$ were observed for PCV and for monocytes, but after 24 hours these had returned to the control level. Although the postexposure lymphocyte count was not significantly different from the control there was, at 24 hours, a small but significant $(P<0.05)$ rise. None of these parameters, however, reached a level which would be regarded as abnormal.

\section{Blood biochemistry}

Table 5 contains the means and standard deviations for the blood biochemistry findings in 16 volunteers measured before, immediately after, and 24 hours after a 60-minute exposure to CS. The volunteers chosen were the same as those for the haematological

TABLE 4

Haematological Data-Means (SD) and Statistical Significance of Mean Differences between Control Values and Post-exposure and 24-hour Values

\begin{tabular}{|c|c|c|c|c|c|c|c|}
\hline & & & \multirow{2}{*}{ Pre } & \multirow{2}{*}{ Post } & \multirow{2}{*}{24 hours } & \multicolumn{2}{|c|}{ Significance } \\
\hline & & & & & & Pre v. post & Pre v. $24 \mathrm{hr}$ \\
\hline $\begin{array}{l}\text { Hb }(\mathrm{g} / 100 \mathrm{ml}) \\
\text { PCV \% ... } \\
\text { MCHC \% . } \\
\text { ESR Wintrobe } \\
\text { WBC/mm }{ }^{3} \ldots \\
\text { Neutrophils } \\
\text { Lymphocytes } \\
\text { Monocytes } \\
\text { Eosinophils } \\
\text { Basophils .. }\end{array}$ & $\begin{array}{l}\cdots \\
\cdots \\
\cdots \\
\cdots \\
\cdots \\
\cdots \\
\cdots \\
\cdots \\
\cdots\end{array}$ & $\begin{array}{l}\ldots \\
\cdots \\
\cdots \\
\cdots \\
\cdots \\
\cdots \\
\cdots \\
\cdots \\
\cdots\end{array}$ & 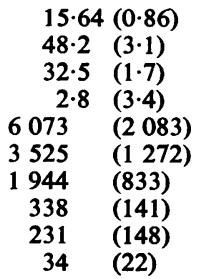 & $\begin{array}{rrl} & 15 \cdot 87 & (0 \cdot 79) \\
& 49 \cdot 4 & (1 \cdot 8) \\
32 \cdot 1 & (0 \cdot 8) \\
& 2 \cdot 6 & (2 \cdot 6) \\
7209 & (1912) \\
7299 & (1366) \\
42235 & (936) \\
22 & 484 & (198) \\
165 & (155) \\
26 & (38)\end{array}$ & 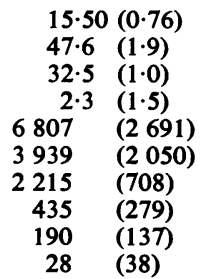 & $\begin{aligned} & \text { NS } \\
&< 0.05 \\
& \text { NS } \\
& \text { NS } \\
&<0.005 \\
&<0.01 \\
& \text { NS } \\
&<0.05 \\
& \text { NS } \\
& \text { NS }\end{aligned}$ & $\begin{array}{c}\text { NS } \\
\text { NS } \\
\text { NS } \\
\text { NS } \\
<0.01 \\
\text { NS } \\
<0.05 \\
\text { NS } \\
\text { NS } \\
\text { NS }\end{array}$ \\
\hline
\end{tabular}


TABLE 5

Biochemical Data-Means (SD) and Statistical Significance of Mean Differences between Control Values and POST-eXPosure and 24-Hour Values

\begin{tabular}{|c|c|c|c|c|c|}
\hline & \multirow{2}{*}{ Pre } & \multirow{2}{*}{ Post } & \multirow{2}{*}{24 hours } & \multicolumn{2}{|c|}{ Significance } \\
\hline & & & & Pre v.post & Pre v. $24 \mathrm{hr}$ \\
\hline 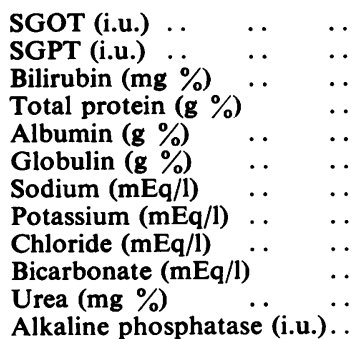 & 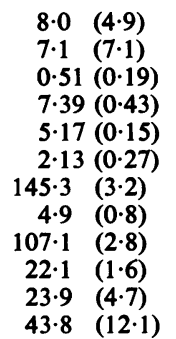 & $\begin{aligned} & 9 \cdot 6(4 \cdot 6) \\
& 8 \cdot 7(7 \cdot 7) \\
& 0 \cdot 42(0 \cdot 15) \\
& 7 \cdot 87(0.42) \\
& 5 \cdot 15(0.08) \\
& 2.90(0.23) \\
& 140 \cdot 7(1 \cdot 7) \\
& 4 \cdot 5(0.5) \\
& 103.5(2 \cdot 1) \\
& 25.4(1.3) \\
& 25.4(6 \cdot 1) \\
& 41.9(11 \cdot 8)\end{aligned}$ & $\begin{aligned} & 9 \cdot 0(5.0) \\
& 7.9(8 \cdot 4) \\
& 0.44(0.20) \\
& 7 \cdot 20(0.43) \\
& 4 \cdot 77(0.10) \\
& 2.55(0.26) \\
& 142.3(1.4) \\
& 4.6(0.4) \\
& 105.2(1.9) \\
& 24.9(0.9) \\
& 24.6(5.9) \\
& 42.0(12 \cdot 6)\end{aligned}$ & $\begin{aligned} & \text { NS } \\
&< 0.05 \\
& \text { NS } \\
&<0.001 \\
&<\text { NS } \\
&<0.001 \\
&<0.01 \\
&<0.05 \\
&<0.01 \\
&<0.001 \\
& \quad \text { NS } \\
& \text { NS }\end{aligned}$ & $\begin{array}{l}\text { NS } \\
\text { NS } \\
\text { NS } \\
\text { NS } \\
<0.05 \\
<0.01 \\
<0.01 \\
\text { NS } \\
<0.05 \\
<0.05 \\
\text { NS } \\
\text { NS }\end{array}$ \\
\hline
\end{tabular}

study. As with the haematological findings there was no evidence of any systematic change of pathological significance occurring as a result of exposure to CS. Some individuals yielded values, including control values, which lay just beyond the limits of accepted normality, but these appear to be incidental.

As with the haematological findings, it was considered appropriate to examine differences between the control values and both the immediate postexposure values and those at 24 hours for their statistical significance.

Immediately after exposure three parameters showed a highly significant rise; these were total protein, globulin, and bicarbonate $(P<0.001)$. However, at 24 hours the first of these had returned to the control level, the second remained moderately raised $(\mathrm{P}<0.01)$, and the third barely raised $(P<0.05)$.

The serum electrolytes showed a post-exposure fall (sodium and chloride $P<0.01$; potassium $P<$ 0.05 ) but, whereas the potassium level was restored to the control value by 24 hours, the other two remained low-chloride $P<0.05$ and sodium $P<$ 0.01 . SGPT was elevated post-exposure but had returned to control levels by 24 hours. It must be emphasized that none of these changes took the absolute value of the parameter to a level which would be regarded as abnormal.

\section{Cardiovascular observations}

Pre- and post-exposure standard limb leads of the electrocardiogram could be obtained from only 10 men. The pattern of the ECG was apparently unaffected following CS exposure but some change in heart rate was observed; thus the mean pre-exposure heart rate was 80 (SD 10) and the mean postexposure rate 67 (SD 5). The differences between them of about 13 beats/min was highly significant $(P<0.001)$. This fall in rate can perhaps be ascribed to the sense of relief experienced by each man at the finish of a decidedly uncomfortable experience.

Changes in blood pressure were sought during the exposure as well as before and after, and a total of 27 subjects was examined. Records were taken in the exposure chamber when the respirator was removed and thereafter at 10,20 , and 50 minutes while the exposure continued. The mean findings are given in Table 6, where the most obvious feature is a steep rise in systolic, diastolic, and pulse pressures on removal of the respirator to levels significantly greater than the control values at 10 minutes $(P<$ 0.001 ). When the 20-minute values are compared with the control values no statistically significant difference can be demonstrated so that it appears that the blood pressure changes are due to the abrupt onset of discomfort rather than to the administration of CS itself.

\section{Respiratory function}

Post CS exposure radiographs showed no differences from those made before exposure. Measurements of peak flow, tidal volume, and vital capacity were made on 26 subjects (Table 7). For simplicity of presentation they have been grouped (see p. 305) so that findings from trials 1 and 3 are together as are findings from trials 5 and 6 . The samples are small and therefore the means may not be representative; where a total of eight subjects have been involved standard deviations are also given. On several occasions the men found it difficult to use the test equipment and failed to provide useful results. The figures of Table 7 reveal no effect of CS, under these experimental conditions, on the three respiratory functions measured. 
TABLE 6

Cardiovascular Findings-Means (SD) and Levels of Significant Differences between Control VAlues AND thOSE AT ReMOVAl OF Respirators AND AFTER 20 minUtes' EXPOSURE to CS

\begin{tabular}{|c|c|c|c|c|c|c|c|}
\hline & & & \multirow{2}{*}{$\begin{array}{c}\text { Pre } \\
(m m \mathrm{Hg})\end{array}$} & \multirow{2}{*}{$\begin{array}{l}\text { Removal of } \\
\text { respirator } \\
(\mathrm{mm} \mathrm{Hg})\end{array}$} & \multirow{2}{*}{$\begin{array}{c}20 \text { minutes } \\
(\mathrm{mm} \mathrm{Hg})\end{array}$} & \multicolumn{2}{|c|}{ Significance } \\
\hline & & & & & & Pre v. removal & Pre v. $20 \mathrm{~min}$ \\
\hline Systolic & .. & .. & $\begin{array}{c}122 \cdot 7 \\
(6 \cdot 5)\end{array}$ & $\begin{array}{c}142 \cdot 0 \\
(8 \cdot 3)\end{array}$ & $\begin{array}{r}123 \cdot 7 \\
(6 \cdot 4)\end{array}$ & $<0.001$ & NS \\
\hline Diastolic & .. & .. & $\begin{array}{l}73 \cdot 1 \\
(7 \cdot 2)\end{array}$ & $\begin{array}{c}84 \cdot 4 \\
(6 \cdot 1)\end{array}$ & $\begin{array}{l}74 \cdot 5 \\
(7 \cdot 0)\end{array}$ & $<0.001$ & NS \\
\hline Pulse pressure & .. & .. & $\begin{array}{l}49 \cdot 4 \\
(7 \cdot 5)\end{array}$ & $\begin{array}{l}57 \cdot 2 \\
(6 \cdot 5)\end{array}$ & $\begin{array}{l}49 \cdot 4 \\
(7 \cdot 1)\end{array}$ & $<0.001$ & NS \\
\hline
\end{tabular}

\section{Discussion}

The principal objective of this investigation was to bring to light any effects of CS which occur following dosages greater than those expected in practical situations. To do this, and to demonstrate the phenomenon of tolerance at the same time, it was considered appropriate to use a combination of a relatively low concentration for a relatively long time. The dosage $\left(\mathrm{Ct}\right.$ in $\mathrm{mg} \cdot \mathrm{min} / \mathrm{m}^{3}$ ) received by individuals exposed to an aerosol is conveniently expressed as the product of the concentration as $\mathrm{mg} / \mathrm{m}^{3}$, and the duration of the exposure in minutes. With CS most individuals are compelled to retreat to clear air at a Ct of about $5 \mathrm{mg} . \mathrm{min} / \mathrm{m}^{3}$; it is likely that some of the men included in this study experienced Cts of between 60 and $90 \mathrm{mg} \cdot \mathrm{min} / \mathrm{m}^{3}$.
The present observations of the signs and symptoms of CS exposure fully confirm previous experience which was summarized in the British Medical Journal in 1970. Clearly, the abrupt onset of the extremely unpleasant effects is a major feature of the action of the agent and it is likely that this mode of onset predisposes to accompanying emotional effects. It is notable that although the symptoms did not go away the individual took less account of them as time went on.

Apart from the eyes, effects are felt principally in the upper and lower respiratory tracts and consist of irritation, soreness in the chest, and difficulty in breathing. The respiratory function tests carried out in this study did not reveal any effect of CS on lung function and this finding conforms with that of Cotes, Dabbs, Evans, and Holland (1972) who could

TABLE 7

COMPARISON OF RESPIRATORY FUNCTION TESTS BEFORE AND AFTER 1 HOUR'S EXPOSURE TO CS

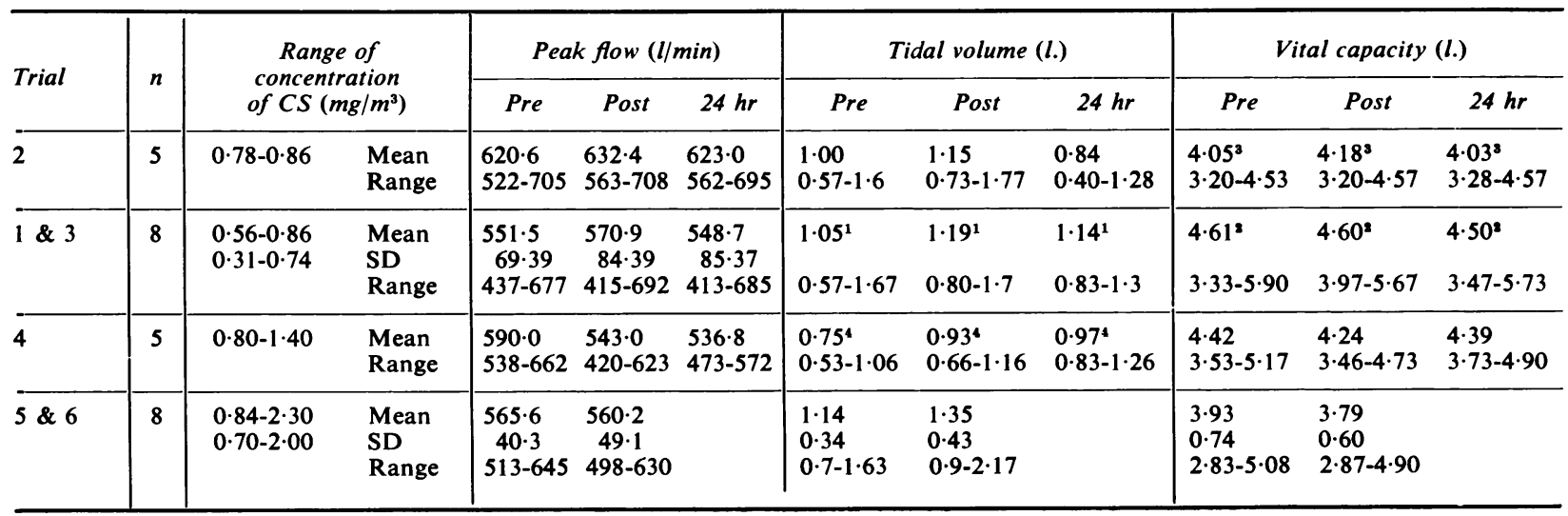

${ }^{1}$ Mean of 5 subjects.

${ }^{2}$ Mean of 6 subjects.

Mean of 4 subjects.

"Mean of 3 subjects. 
not find any effect on pulmonary gas transfer or alveolar volume using the single breath carbon monoxide method after one hour's exposure to CS aerosols. The mean concentration of CS used in their experiments was $0.62 \mathrm{mg} / \mathrm{m}^{3}$ at the start, rising to $2.00 \mathrm{mg} / \mathrm{m}^{3}$ after one hour. The effect of these concentrations of CS, or even higher concentrations, on individuals with lung disease could therefore not be deduced.

The changes detected in blood, blood pressure, and heart rate are not of the type to be regarded as sinister. The changes in blood pressure fall into line with the fluctuating intensity of the symptoms referred to above. At 20 minutes, although still exposed, the pressor effect of the stimulus had apparently gone; similarly, the pulse rates of the volunteers had reached control values after the end of the 60-minute exposure. More difficult to account for are the changes in certain blood values, but it must be emphasized that none of these changes can be regarded as pathological. If the cause is physiological then it is one which is associated with stress and the obvious choice is the over-production of adrenaline; thus the raised total leucocyte count and plasma protein are typical effects of adrenaline action. Unfortunately, blood lactate levels, also affected by adrenaline, were not measured but changes in lactate will affect the other ionic constituents of the plasma.

It appears therefore that the true effects of CS are those due to local irritation of exposed nerve endings. Any systemic changes demonstrated so far are those due to stress and they cannot be regarded as specific to CS.
We are indebted to D. Parkes, Judith Shakespeare, A. Wetherell, Barbara Collinge, and T. Aldous for technical assistance.

The data which form the basis of this investigation were reported to the Committee of Enquiry into the Medical and Toxicological Aspects of CS and are referred to in Part II of the Report (H.M.S.O., Cmnd 4775) by that Committee as Reference 9, Committee Report 7253/70).

\section{References}

Ballantyne, B., and Callaway, S. (1972a). Inhalation toxicology and pathology of animals exposed to o-chlorobenzylidene malononitrile (CS). Med. Sci. Law, 12, 43-65.

- and - (1972b). Studies on the acute oral and parenteral toxicity of ortho-chlorobenzylidene malononitrile (CS). In preparation.

British Medical Journal (1970). First aid after CS exposure. 2, 783.

Cotes, J. E., Dabbs, J. M., Evans, M. R., and Holland, P. (1972). Possible effects of CS upon lung gas transfer and alveolar volume in healthy men. Quart. J. Exp. Physiol., In press.

Finn, D. H., Hogg, M. A. P., and Crichton, D. (1960). Improvements in apparatus for controlling riots. CS Patent No. 967660. London.

Punte, C. L., Owens, E. J., and Gutentag, P. J. (1963). Exposures to ortho-chlorobenzylidene malononitrilecontrolled human exposure. Arch. environm. Hlth, 6, 366-374.

Stein, A. A., and Kirwan, W. E. (1964). Chloroacetophenone (tear gas) poisoning. A clinico-pathological report. $J$. forens. Sci., 9, 374-382.

Received for publication October 28, 1971. 